\title{
Effects of fresh and aged chars from pyrolysis and hydrothermal carbonization on nutrient sorption in agricultural soils
}

\author{
M. Gronwald, A. Don, B. Tiemeyer, and M. Helfrich \\ Thünen Institute of Climate-Smart Agriculture, Bundesallee 50, 38116 Braunschweig, Germany \\ Correspondence to: A. Don (axel.don@ti.bund.de)
}

Received: 7 January 2015 - Published in SOIL Discuss.: 14 January 2015

Revised: 18 May 2015 - Accepted: 1 June 2015 - Published: 18 June 2015

\begin{abstract}
Leaching of nutrients from agricultural soils causes major environmental problems that may be reduced with amendments of chars derived from pyrolysis (pyrochars) or hydrothermal carbonization (hydrochars). Chars are characterized by a high adsorption capacity - i.e. they may retain nutrients such as nitrate and ammonium. However, the physicochemical properties of the chars and hence their sorption capacity likely depend on feedstock and the production process. We investigated the nutrient retention capacity of pyrochars and hydrochars from three different feedstocks (digestates, Miscanthus, woodchips) mixed into different soil substrates (sandy loam and silty loam). Moreover, we investigated the influence of char degradation on its nutrient retention capacity using a 7-month in situ field incubation of pyrochar and hydrochar mixed into soils at three different field sites. Pyrochars showed the highest ability to retain nitrate, ammonium and phosphate, with pyrochar from woodchips being particularly efficient in nitrate adsorption. Ammonium adsorption of pyrochars was controlled by the soil type of the soil-char mixture. We found some ammonium retention on sandy soils, but no pyrochar effect or even ammonium leaching from the loamy soil. The phosphate retention capacity of pyrochars strongly depended on the pyrochar feedstock with large phosphate leaching from digestate-derived pyrochar and some adsorption capacity from woodchip-derived pyrochar. Application of hydrochars to agricultural soils caused small, and often not significant, effects on nutrient retention. In contrast, some hydrochars did increase the leaching of nutrients compared to the non-amended control soil. We found a surprisingly rapid loss of the chars' adsorption capacity after field application of the chars. For all sites and for hydrochar and pyrochar, the adsorption capacity was reduced by $60-80 \%$ to less or no nitrate and ammonium adsorption. Thus, our results cast doubt on the efficiency of char applications to temperate zone soils to minimize nutrient losses via leaching.
\end{abstract}

\section{Introduction}

Excessive application of mineral fertilizers to agricultural soils is one of the major drivers for various threats to the environment (Laird et al., 2010; Liang et al., 2006). An excess of nutrients may induce soil acidification, increase direct and indirect greenhouse gas emissions (Karaca et al., 2004), and cause eutrophication of the receiving water bodies. However, mineral fertilization has also been the major driver for increased global agricultural production during the last decades. Therefore, technologies are required to both decrease nutrient leaching from soils and enhance nutrient use efficiency with the result that less fertilizer is needed. Amendment of soils with chars is proposed as one promising option to retain nutrients and prevent leaching (Lehmann and Joseph, 2009).

These chars are the solid charcoal product derived from the thermal transformation of a variety of organic feedstocks such as digestates, sewage sludge, woods, and other forestry or agricultural residues (Hale et al., 2013; Yao et al., 2012). At present, two main processes for the production of chars that are intended for application to soil are used: the first production process, slow pyrolysis, is the combustion and conversion of biomass at processing temperatures above $450^{\circ} \mathrm{C}$ 
under oxygen-free conditions. In the following, the solid product derived from pyrolysis will be termed pyrochar. Pyrochars are characterized by a high degree of aromaticity (Keiluweit et al., 2010; Lehmann et al., 2006) and recalcitrance against degradation or mineralization (Glaser et al., 2002). Second, hydrothermal carbonization (HTC) is a lowtemperature production process (temperatures between 180 and $\left.300^{\circ} \mathrm{C}\right)$ under high pressure $(2-2.5 \mathrm{MPa})$ with water for several hours (Funke and Ziegler, 2010; Libra et al., 2011; Wiedner et al., 2013). In the following, we will refer to the solid product from the HTC as hydrochar. Hydrochars have recently received increasing attention since wet feedstock can also be carbonized without drying pretreatment (Funke and Ziegler, 2010). Hydrochars are characterized by a lower degree of carbonization and thus more aliphatic carbon (C) but smaller amounts of aromatic $\mathrm{C}$ and lower specific surface area (SSA) compared to pyrochars (Eibisch et al., 2013; Titirici et al., 2008). Besides general differences between pyrochar and hydrochar, their properties differ strongly depending on the feedstock, carbonization processes parameters, and subsequent thermochemical reactions (Cantrell et al., 2012; Cao et al., 2011; Eibisch et al., 2013, 2015; Yao et al., 2012).

For the past 10 years, the application of pyrochar, and later on of hydrochar, to agricultural soils has become a center of attention as an option to store atmospheric $\mathrm{C}$ in soil to mitigate global warming. Additionally, a variety of positive co-benefits are attributed to pyrochar-amended soils: an increase in water retention capacity (Glaser et al., 2002; Abel et al., 2013); reduction of greenhouse gas emissions such as nitrous oxide $\left(\mathrm{N}_{2} \mathrm{O}\right)$ and methane $\left(\mathrm{CH}_{4}\right)$; and an enhanced crop productivity due to the retention of plant available nutrients in the rhizosphere (Lehmann and Joseph, 2009), increased soil $\mathrm{pH}$ and soil cation exchange capacity (CEC) (Liang et al., 2006), and preservation of toxic compounds (Chen and Yuan, 2011).

Both pyrochars and hydrochars contain nutrients which can be released slowly into the rhizosphere (Eibisch et al., 2013; Spokas et al., 2011; Taghizadeh-Toosi et al., 2011), but more important is the pyrochars' ability to adsorb nutrients due to its high surface charge density and CEC. The leaching and adsorption of nitrate $\left(\mathrm{NO}_{3}^{-}\right)$, ammonium $\left(\mathrm{NH}_{4}^{+}\right)$, and phosphate $\left(\mathrm{PO}_{4}^{3-}\right)$ to various activated $\mathrm{C}$ and charcoals has been studied (Bandosz and Petit, 2009; Ding et al., 2010). However, studies concerning the sorption behavior of pyrochar, and especially hydrochars, are rare. Previous studies focusing on soil-char mixtures have shown that leaching of $\mathrm{NO}_{3}^{-}, \mathrm{NH}_{4}^{+}$, and $\mathrm{PO}_{4}^{3-}$ from soils amended with pyrochar or hydrochar was frequently reduced due to adsorption on the respective char (Bargmann et al., 2014b; Ding et al., 2010; Laird et al., 2010; Sarkhot et al., 2012). Laird et al. (2010) applied $20 \mathrm{~g} \mathrm{~kg}^{-1}$ pyrochar from hardwood to an agricultural soil, which decreased the leaching of $\mathrm{NO}_{3}^{-}$from swine manure by $10 \%$. Yao et al. (2012) reported increased
$\mathrm{NO}_{3}^{-}$adsorption of up to $4 \%$, as well as leaching rates of up to $8 \%$ from aqueous solution. Other studies showed that $\mathrm{NO}_{3}^{-}$(Castaldi et al., 2011; Hale et al., 2013; Jones et al., 2012), as well as $\mathrm{NH}_{4}^{+}$leaching, was decreased by $94 \%$ due to pyrochar application to a Ferralsol in a 37-day soil column leaching experiment (Lehmann et al., 2003). Furthermore, both $\mathrm{NH}_{4}^{+}$adsorption by up to $15 \%$ from aqueous solution and leaching by up to $4 \%$ into solution were observed (Yao et al., 2012). Other nutrients which are not particularly prone to leaching, such as $\mathrm{PO}_{4}^{3-}$, have also been reported to be retained by application of pyrochar (Laird et al., 2010; Morales et al., 2013; Xu et al., 2014). For example, Laird et al. (2010) reported up to $70 \%$ reduced $\mathrm{PO}_{4}^{3-}$-P leaching in a soil column experiment mixed with $20 \mathrm{~g} \mathrm{~kg}^{-1}$ pyrochar. In contrast, Yao et al. (2012) observed up to $5 \% \mathrm{PO}_{4}^{3-}$-P leaching from aqueous solution for pyrochars from bamboo and hydrochars from peanut hull. In summary, these studies imply a strong variation in leaching or retention behavior of chars, which seems to depend on feedstock and production process.

Char application has been promised to be multi-beneficial. However, benefits have been tested mostly for pyrocharamended tropical soils with few comparative studies for temperate soils or hydrochars. This is one of the main reasons why neither pyrochar nor hydrochar application is considered in agricultural practice in the temperate zone at the moment. Even though chars, especially pyrochars, are relatively stable in soils, an increasing number of studies have suggested that biotic and abiotic processes can lead to degradation of char and thus change its surface properties and sorption behavior (Cheng et al., 2008; Hale et al., 2011; Liu et al., 2013; Steinbeiss et al., 2009). The physical structure and chemical properties of hydrochars result in a lower recalcitrance towards microbial degradation compared to pyrochars (Bargmann et al., 2014a; Hale et al., 2011; Steinbeiss et al., 2009). Furthermore, hydrochars release a higher amount of dissolved organic carbon (DOC) which might be easily mineralized. Hence, soil amended with hydrochars increases microbial-biomass production and immobilization of mineral nitrogen (Bargmann et al., 2014a; Lehmann et al., 2011), and an increased nitrification from $\mathrm{NH}_{4}^{+}$to $\mathrm{NO}_{3}^{-}$may occur. Over time, slow char aging due to oxidation may lead to carboxylic and phenolic functional groups on the chars' surface and thus negative charges. On the other hand, the atomic $\mathrm{C}$ content and positive surface charge on the edge sites of aromatic compounds will be reduced (Cheng et al., 2008, 2006; Glaser et al., 2000). Furthermore, surface oxidation increases CEC per unit $\mathrm{C}$ and the charge density (Liang et al., 2006), but a higher anion exchange capacity (AEC) has been found for aged pyrochars as well (Mukherjee et al., 2011). At the same time, pyrochars may adsorb organic matter $(\mathrm{OM})$, which blocks char surfaces and reduces their sorption capacity (Mukherjee et al., 2011). However, so far these long-term changes in char properties and consecutive 
functions have been ignored in most char studies on nutrient retention, which may lead to systematic bias.

In summary, according to the majority of studies (Hale et al., 2013; Knowles et al., 2011; Lehmann et al., 2003; Morales et al., 2013; Xu et al., 2014), char may be a potential melioration for soils by decreasing nutrient leaching via improved adsorption properties. However, there is only little knowledge on the nutrient sorption potential of pyrochars compared to hydrochars, and the influence of aging/degradation on nutrient sorption.

The influence of char properties resulting from different carbonization methods and different feedstock materials on nutrient sorption potential is also insufficiently understood. Furthermore, no systematic comparison of different feedstock materials on nutrient sorption has yet been conducted, and the effect of aging of chars on their sorption potential has not yet been investigated. The objectives of this study are to first determine the nutrient sorption potential of nine different char-soil mixtures in laboratory batch experiments and to investigate the influence of (i) char type (pyrochar vs. hydrochar), (ii) soil type (sandy loam vs. silty loam), and (iii) char feedstock (woodchips, digestate, and Miscanthus). Secondly, we want to assess the effect of aged vs. fresh chars (pyrochar and hydrochar from Miscanthus) on nutrient sorption potential in a field experiment.

\section{Materials and methods}

\subsection{Production and general properties of pyrochars and hydrochars and their corresponding feedstocks}

The nine chars that were used for laboratory batch experiments originated from the same setup as the chars described in Eibisch et al. (2013, 2015). These chars were derived from HTC and pyrolysis and were produced from three feedstock materials with different physicochemical properties (digestates (99\% maize), woodchips (95\% poplar, $5 \%$ willow), and Miscanthus). The hydrochars were carbonized with water $(1: 10, w / w)$ in a batch reactor for $6 \mathrm{~h}$ with a pressure of $2 \mathrm{MPa}$ at 200 (hereafter referred to as Hydro200) and $250^{\circ} \mathrm{C}$ (hereafter referred to as Hydro250; SmartCarbon AG, Jettingen, Germany). Pyrochars were produced in a Pyreg reactor (PYREG GmbH, Dörth) for $0.75 \mathrm{~h}$ at $750^{\circ} \mathrm{C}$ (designated hereafter as Pyro750). Detailed information on char preparation and methods of analysis (e.g., specific surface area (SSA), pore volume, average pore size) can be found in Eibisch et al. (2013, 2015).

In order to simulate field aging, we compared unwashed chars with washed chars in the laboratory experiment. Washing was assumed to be capable of simulating aging of the char as initially bound nutrients or salts would be removed. Washing was carried out by shaking $4.5 \mathrm{~g}$ of biochar with $1 \mathrm{~L}$ of deionized water in an overhead shaker at $9 \mathrm{rpm}$ for $4 \mathrm{~h}$ and thereafter the solution was filtered with pleated paper filter (grade: $3 \mathrm{hw}$; diameter: $150 \mathrm{~mm} ; 65 \mathrm{~g} \mathrm{~m}^{-2}$ ) and filtrate (py- rochar or hydrochar) was dried for $24 \mathrm{~h}$ at $105^{\circ} \mathrm{C}$. Washing effects were only studied in the pyrochar and hydrochar applied to silty loam mixtures, because highest nutrient leaching or adsorption effects were expected for this soil.

\subsection{Field aging}

Hydrochar and pyrochar produced from Miscanthus was used for the field incubation. The hydrochar was carbonized with water $(1: 10, w / w)$ in a tabular reactor $\left(3 \mathrm{~m}^{3}\right)$ for $11 \mathrm{~h}$ with a pressure of $2 \mathrm{MPa}$ at $200^{\circ} \mathrm{C}$ by AddLogicLabs/SmartCarbon (Jettingen, Germany). Citric acid was added as a catalyst for the dehydration process and to increase the C content in the solid product (Wang et al., 2010). Pyrochars were produced in a Pyreg reactor for $0.75 \mathrm{~h}$ at $750{ }^{\circ} \mathrm{C}$. Analyses of general properties of the chars and raw material were carried out by Andrea Kruse (KIT, Karlsruhe). All chars were dried at $40^{\circ} \mathrm{C}$ and sieved $\leq 2 \mathrm{~mm}$. Basic characteristics of feedstocks, pyrochars, and hydrochars for the laboratory batch and field incubation experiment are listed in Table 1.

For the investigation of the effect of aging of the chars in the field, chars were incubated in situ at three cropland sites in the North German lowland (mean annual temperature $8.8^{\circ} \mathrm{C}$, around $600 \mathrm{~mm}$ precipitation). The three sites differ mainly in their soil texture (Table 2 ) and are located in Bortfeld (sandy loam (SL); $52^{\circ} 28^{\prime} \mathrm{N}, 10^{\circ} 41^{\prime} \mathrm{E}$; $80 \mathrm{~m}$ a.s.l.), Volkmarsdorf (sandy loam (SL); 52 $36^{\prime} \mathrm{N}, 10^{\circ} 89^{\prime} \mathrm{E} ; 105 \mathrm{~m}$ a.s.1.), and Querenhorst (loamy sand (LS); $52^{\circ} 33^{\prime} \mathrm{N}, 10^{\circ} 96^{\prime} \mathrm{E}$; $112 \mathrm{ma.s.1.).} \mathrm{All} \mathrm{sites} \mathrm{were} \mathrm{managed} \mathrm{according} \mathrm{to} \mathrm{com-}$ mon regional practice with conventional tillage and fertilizing. Crop rotations were barley (2012), winter wheat (cover crop), and sugar beet (2013) (Querenhorst); barley (2012), mustard (cover crop), and sugar beet (2013) (Volkmarsdorf); and potatoes (2012) and sugar beet (2013) (Bortfeld). At all three sites, mini-plots (plot size: $70 \times 70 \mathrm{~cm}$; plot depth: $25 \mathrm{~cm}$ ) were dug out in triplicate in March 2013, and the hydrochar and pyrochar were mixed into the soil in a cement mixer in an amount that aimed to double the soils' $\mathrm{C}$ content (corresponding to around $100 \mathrm{tha}^{-1}$ char). The experimental setup was a randomized plot design carried out in three rows for each site so that every row consisted of three treatments: (i) control (soil only), (ii) soil + hydrochar, and (iii) soil + pyrochar. In order to distinguish the soils' C contents from treated or non-treated soil, and to quantify any blending or attenuation with the surrounding soil, e.g., due to tillage, $105 \mathrm{~g}$ of zinc as an inert tracer was added to each treatment in the cement mixer (control, pyrochar + soil, hydrochar + soil). The mini-plots were not fenced off, so the farmers were able to manage the fields exactly like to the rest of the field.

Sampling was carried out twice: the first set of soil samples was taken in March 2013 right after mixing the soil with chars $\left(T_{0}\right)$. After 7 months (October 2013) a second sampling was carried out $\left(T_{1}\right)$. Soil samples were obtained by taking 


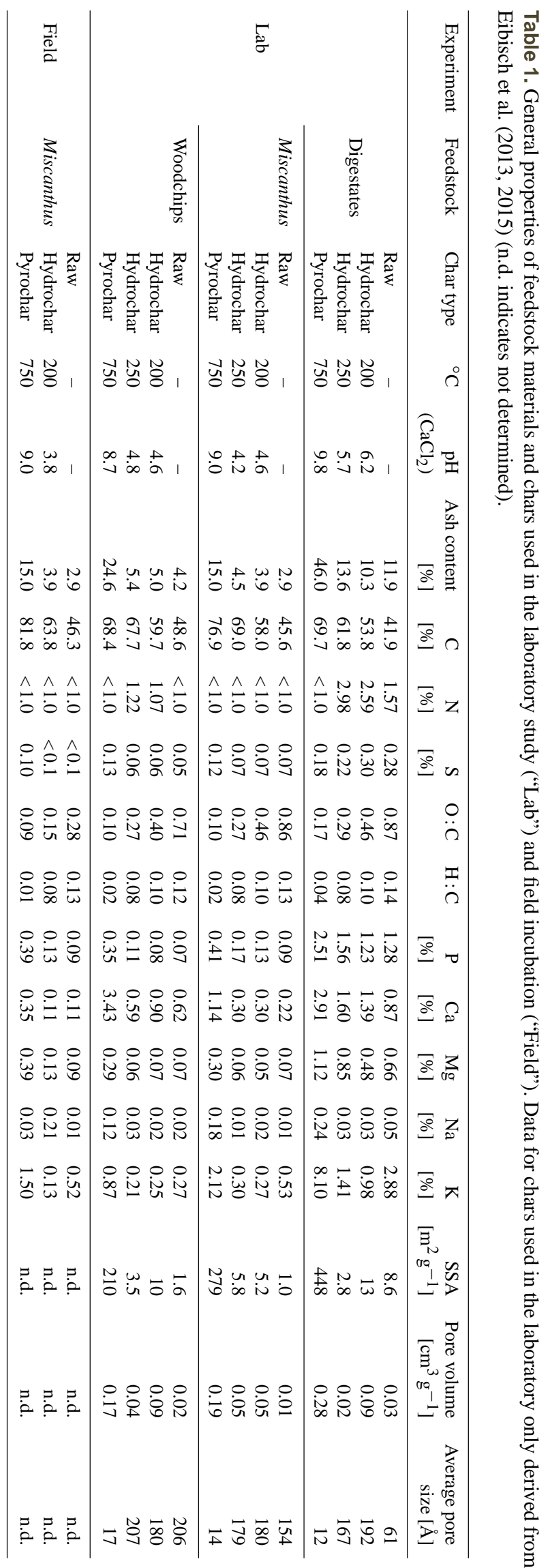


Table 2. General properties of the soils used for the lab and field study (n.d. indicates not determined).

\begin{tabular}{|c|c|c|c|c|c|c|c|c|c|c|c|c|}
\hline Experiment & & Site & Soil type & $\begin{array}{l}\text { Soil texture } \\
\text { class }\end{array}$ & $\begin{array}{r}\text { Sand } \\
{[\%]}\end{array}$ & $\begin{array}{l}\text { Silt } \\
{[\%]}\end{array}$ & $\begin{array}{r}\text { Clay } \\
{[\%]}\end{array}$ & $\begin{array}{c}\mathrm{C}_{\text {org }} \\
{[\%]}\end{array}$ & $\begin{array}{l}\mathrm{N}_{\text {tot }} \\
{[\%]}\end{array}$ & $\mathrm{C} / \mathrm{N}$ & $\begin{array}{r}\mathrm{pH} \\
\left(\mathrm{CaCl}_{2}\right)\end{array}$ & $\begin{array}{r}\mathrm{CEC} \\
{\left[\mathrm{cmol}_{c} \mathrm{~kg}^{-1}\right]}\end{array}$ \\
\hline \multirow{2}{*}{$\mathrm{Lab}$} & 1 & Göttingen & Haplic Luvisol & Sandy loam & 61.5 & 32.8 & 5.8 & 1.23 & 0.10 & 12.3 & 5.6 & 4.0 \\
\hline & 2 & Braunschweig & Haplic Cambisol & Silty loam & 15.4 & 67.6 & 17.0 & 1.27 & 0.12 & 10.6 & 5.6 & 10.8 \\
\hline \multirow{3}{*}{ Field } & 1 & Bortfeld & Loamic Cambisol & Sandy loam & 57.0 & 37.1 & 5.9 & 0.93 & 0.13 & 7.3 & 6.4 & n.d. \\
\hline & 2 & Querenhorst & Arenic Planosol & Loamy sand & 74.7 & 18.0 & 7.3 & 1.13 & 0.13 & 8.8 & 6.8 & n.d. \\
\hline & 3 & Volkmarsdorf & Cambic Planosol & Sandy loam & 67.1 & 21.7 & 11.2 & 1.16 & 0.12 & 9.9 & 6.5 & n.d. \\
\hline
\end{tabular}

five randomly distributed soil cores to a depth of $25 \mathrm{~cm}$ with a split-tube sampler $(5 \mathrm{~cm}$ diameter) from each mini-plot. Afterwards, samples were dried at $40^{\circ} \mathrm{C}$ and sieved $\leq 2 \mathrm{~mm}$. Zinc concentrations at $T_{0}$ and $T_{1}$ were used to calculate a correction factor $F_{Z}$, which determines the recovery rate of incubated biochars in the field study

\subsection{Batch sorption experiments}

Soil-char mixtures used solely in the laboratory were produced by mixing $0.5 \mathrm{~g}$ of char with $10 \mathrm{~g}$ of soil in order to roughly double the soil's $\mathrm{C}$ content. Two soils were used for the char-soil mixtures: a silt loam (Blagodatskaya et al., 2014) from a cropland site at the Thünen Institute in Braunschweig, Germany $\left(52^{\circ} 17^{\prime} \mathrm{N}, 10^{\circ} 26^{\prime} \mathrm{E} ; 80 \mathrm{~m}\right.$ a.s.l.), and a sandy loam from a cropland site of the University of Göttingen (Reinshof), Germany ( $51^{\circ} 28^{\prime} \mathrm{N}, 9^{\circ} 58^{\prime} \mathrm{E} ; 205 \mathrm{~m}$ a.s.l.). The soil was dried at $105^{\circ} \mathrm{C}$ to inhibit any microbial activity and sieved $\leq 2 \mathrm{~mm}$. The $\mathrm{pH}$ value of soils and chars was measured in $0.01 \mathrm{M} \mathrm{CaCl}_{2}$ with a ratio of $1: 5$ (volume soil / volume solution). Carbon and $\mathrm{N}$ contents were determined using dry combustion with an elemental analyzer (LECO TruMac CN, LECO Corp., St. Joseph, MI, USA). Soil texture was determined by the combined sieve and pipette method.

Preliminary sorption kinetic experiments were conducted to determine the sorption equilibrium by shaking the batches for $4,8,12,24$, and $48 \mathrm{~h}$ at $9 \mathrm{rpm}$ in an overhead shaker. Based on the results of the kinetic experiments, shaking time for the determination of the sorption isotherms was set to $24 \mathrm{~h}$. Soil-char mixtures and $10.5 \mathrm{~g}$ of soil only (control) were added to $40 \mathrm{~mL}$ of a nutrient solution in a $50 \mathrm{~mL}$ plastic centrifuge tube. Six concentration levels of a nutrient solution containing several nutrients that were chosen in order to mimic a "typical" agricultural soil solution were used (Table 3 ). In addition, the $\mathrm{pH}$ value of the solution was adjusted to 6 by adding $\mathrm{HCl}$. Triplicates were measured for each concentration level. The $\mathrm{pH}$ was measured immediately after shaking in the char/soil-solution mixtures. Thereafter, suspensions were centrifuged at $4500 \mathrm{rpm}$ for $30 \mathrm{~min}$. The supernatant was aspirated with a syringe and filtered through $0.45 \mu \mathrm{m}$ membrane filters (CHROMAFIL PET-45/25 disposable syringe filters, Macherey-Nagel). The ion concentrations of the filtrates were analyzed using ion chromatogra- phy (IC) (METROHM 761) for anions $\left(\mathrm{NO}_{3}^{-}, \mathrm{PO}_{4}^{3-}\right)$ and inductively coupled plasma chromatography (ICP) (ICS-90 Dionex/Thermo Fisher Scientific) for cations $\left(\mathrm{NH}_{4}^{+}\right)$. Moreover, contents of $\mathrm{Ca}^{2+}, \mathrm{Mg}^{2+}, \mathrm{K}^{+}$, and $\mathrm{SO}_{4}^{2-}$ were also determined, and fitted isotherms can be found in Table S1 in the Supplement. The potential CEC of separate soil-char mixtures was determined following ISO 13536.

Soil-char mixtures from the field experiment were used directly in the batch sorption experiments $\left(\mathrm{NO}_{3}^{-}, \mathrm{NH}_{4}^{+}, \mathrm{PO}_{4}^{3-}\right)$, which were carried out as described above. To calculate the char adsorption effect relative to the control we used the following equations:

Relative adsorption of the control:

$Q_{\mathrm{Ctrl}}=\left(1-\left(\frac{\mathrm{IC}_{\mathrm{Ctrl}}}{\mathrm{IC}_{\mathrm{Blind}}}\right)\right) \times 100$.

Relative adsorption of the char treatment to control:

$Q_{\mathrm{Char}}=\left(1-\left(\frac{\mathrm{IC}_{\mathrm{Char}}}{\mathrm{IC}_{\mathrm{Ctrl}}}\right)\right) \times F_{Z} \times 100$,

whereby $F_{Z}$ was only used to calculate relative adsorption for field incubated chars. IC is the equilibrium ion content of the nutrient solution after shaking for blinds $\left(\mathrm{IC}_{\mathrm{Blind}}\right)$, control ( $\left.\mathrm{IC}_{\mathrm{Ctrl}}\right)$, or soil-char mixtures ( $\left.\mathrm{IC}_{\mathrm{Char}}\right)$.

\subsection{Statistical analyses}

Adsorption data were fit to Freundlich and linear adsorption isotherms:

Freundlich isotherm: $Q_{e}=K_{\mathrm{F}} \times \mathrm{IC}^{\frac{1}{n}}$,

Linear isotherm : $Q_{e}=a \times \mathrm{IC}+Y_{0}$.

$Q_{e}$ is the amount of ion adsorbed, while IC is the concentration in the solution after $24 \mathrm{~h}$ equilibration. A positive $Q_{e}$ indicates adsorption of ions in the nutrient solution on an adsorbent and a negative $Q_{e}$ desorption from adsorbent to the nutrient solution.

Logarithmized equilibrium concentration and logadsorbed amount was used to calculate the Freundlich sorption partitioning coefficients $\left(K_{\mathrm{F}}\right)$ and the Freundlich exponents $\left(\frac{1}{n}\right)$ following nonlinear fitting. For linear isotherm, $Y_{0}$ is the intercept. 
Table 3. Ion concentrations of the nutrient solution and relative sorption rates of the two control soils (soil without application of char) at the six applied concentration levels.

\begin{tabular}{llrrrrrr}
\hline & Ion & $\mathrm{P} 1$ & $\mathrm{P} 2$ & $\mathrm{P} 3$ & $\mathrm{P} 4$ & $\mathrm{P} 5$ & $\mathrm{P} 6$ \\
\hline \multirow{4}{*}{ Nutrient solution } & $\mathrm{NO}_{3}^{-}-\mathrm{N}\left[\mathrm{mg} \mathrm{L}^{-1}\right]$ & 5 & 10 & 20 & 30 & 40 & 60 \\
& $\mathrm{NH}_{4}^{+}-\mathrm{N}\left[\mathrm{mg} \mathrm{L}^{-1}\right]$ & 5 & 10 & 20 & 30 & 40 & 60 \\
& $\mathrm{PO}_{4}^{3-}-\mathrm{P}\left[\mathrm{mg} \mathrm{L}^{-1}\right]$ & 1.25 & 2.5 & 5 & 7.5 & 10 & 15 \\
\hline \multirow{5}{*}{ Sandy loam } & $\mathrm{NO}_{3}^{-}-\mathrm{N}[\%]$ & -6 & 0.1 & 3 & 0 & 0.1 & 0 \\
& $\mathrm{NH}_{4}^{+}-\mathrm{N}[\%]$ & 15 & 15 & 16 & 15 & 16 & 11 \\
& $\mathrm{PO}_{4}^{3-}-\mathrm{P}[\%]$ & -78 & 6 & 50 & 59 & 57 & 65 \\
\hline \multirow{5}{*}{ Silty loam } & $\mathrm{NO}_{3}^{-}-\mathrm{N}[\%]$ & -58 & -28 & -16 & -8 & -9 & -5 \\
& $\mathrm{NH}_{4}^{+}-\mathrm{N}[\%]$ & 54 & 52 & 49 & 39 & 36 & 33 \\
& $\mathrm{PO}_{4}^{3-}-\mathrm{P}[\%]$ & 10 & 45 & 75 & 73 & 69 & 81 \\
\hline
\end{tabular}

The Akaike information criterion (AIC) was used to select the best-fitting isothermal model. Significance of treatment effects on shape of isotherms was tested using two procedures:

i. If, for two treatments, the same model type resulted in the best fit, their difference was tested with a likelihoodratio test. It was tested whether fitting the model to the data separately resulted in a better fit than fitting the model to the combined data. If the separately fitted model resulted in a better fit than the combined model, treatments were different with their corresponding $p$ value. This test could only be conducted if it was numerically possible to fit the model to the combined data.

ii. Generalized additive models (GAM, R package gam; Hastie, 2013), including and excluding treatment as a predictor, were fitted and compared using analysis of deviance with $\chi^{2}$ statistics.

All $p$ values were adjusted for multiple testing using the procedure of Benjamini and Hochberg (1995). All statistical analyses were conducted using R 3.1.1 (R Core Team, 2014). The results of the statistical analyses can be found in the Supplement (Tables S1, S3, S5, S7, and S8). Significant differences between washed an unwashed chars were tested with the unpaired $t$ test.

\section{Results}

\subsection{Physicochemical properties of the chars}

The $\mathrm{pH}$ values of the hydrochars were acidic ranging from 3.8 to 6.2 and 4.2 to 5.7 for Hydro200 (hydrochars produced at $200^{\circ} \mathrm{C}$ ) and Hydro250 (hydrochars produced at $250^{\circ} \mathrm{C}$ ), respectively (Table 1). The $\mathrm{pH}$ values of Pyro750 (pyrochars produced at $750{ }^{\circ} \mathrm{C}$ ) were alkaline (8.7 to 9.8$)$. The ash content increased with increasing carbonization temperature and was highest for pyrochars from woodchips (24.6\%). Generally, woodchips had the highest $\mathrm{C}$ concentration $(48.6 \% \mathrm{C})$ as a raw material, but after carbonization, Pyro750 from Miscanthus had the highest $\mathrm{C}$ concentrations (Lab: $76.9 \% \mathrm{C}$; Field: $81.8 \% \mathrm{C}$ ). The highest amounts of total $\mathrm{N}$ and $\mathrm{P}$ were found in Hydro200 and Hydro250 from digestates. After carbonization, highest SSA was observed for pyrochars and decreased in the order Pyro750 > Hydro200 > Hydro250 (Table 1). Pyro750 showed the highest pore volume, followed by Hydro200 and Hydro250. In general, Pyro750 showed smaller average pore size than Hydro200 and 250 by a factor of 10 .

\subsection{Influence of soil, feedstock, and carbonization type on nutrient sorption (laboratory experiments)}

Figures 1,2, and 3 show the relative change in ion concentrations of the char treatments from the three feedstocks (triangles: Miscanthus; circles: digestates; squares: woodchips) to the control ( $0 \%$ line) at all applied nutrient concentration levels. Positive values correspond to adsorption and negative values to leaching.

\subsubsection{Sorption of nitrate}

The pure sandy loam (control in Table 3) showed neither $\mathrm{NO}_{3}^{-}$sorption nor release (all data points are around $0 \%$ ). In contrast, the pure silty loam tended towards a high $\mathrm{NO}_{3}^{-}$ release of around $60 \%$ : at the lowest concentration level of the nutrient solution (Table 3). This release decreased to $5 \%$ with increasing concentrations of the nutrient solution.

Mixing soil with Pyro750 significantly reduced $\mathrm{NO}_{3}^{-}$ leaching, independent of the soil and feedstock used (Fig. 1a, b). The relative amount of adsorbed $\mathrm{NO}_{3}^{-}$in pyrocharamended soils was higher in sandy loam than in silty loam. At the lowest concentration level of the nutrient solution, application of Pyro750 raised $\mathrm{NO}_{3}^{-}$adsorption between 2 and $15 \%$ (silty loam) and 7 and $30 \%$ (sandy loam) compared to 


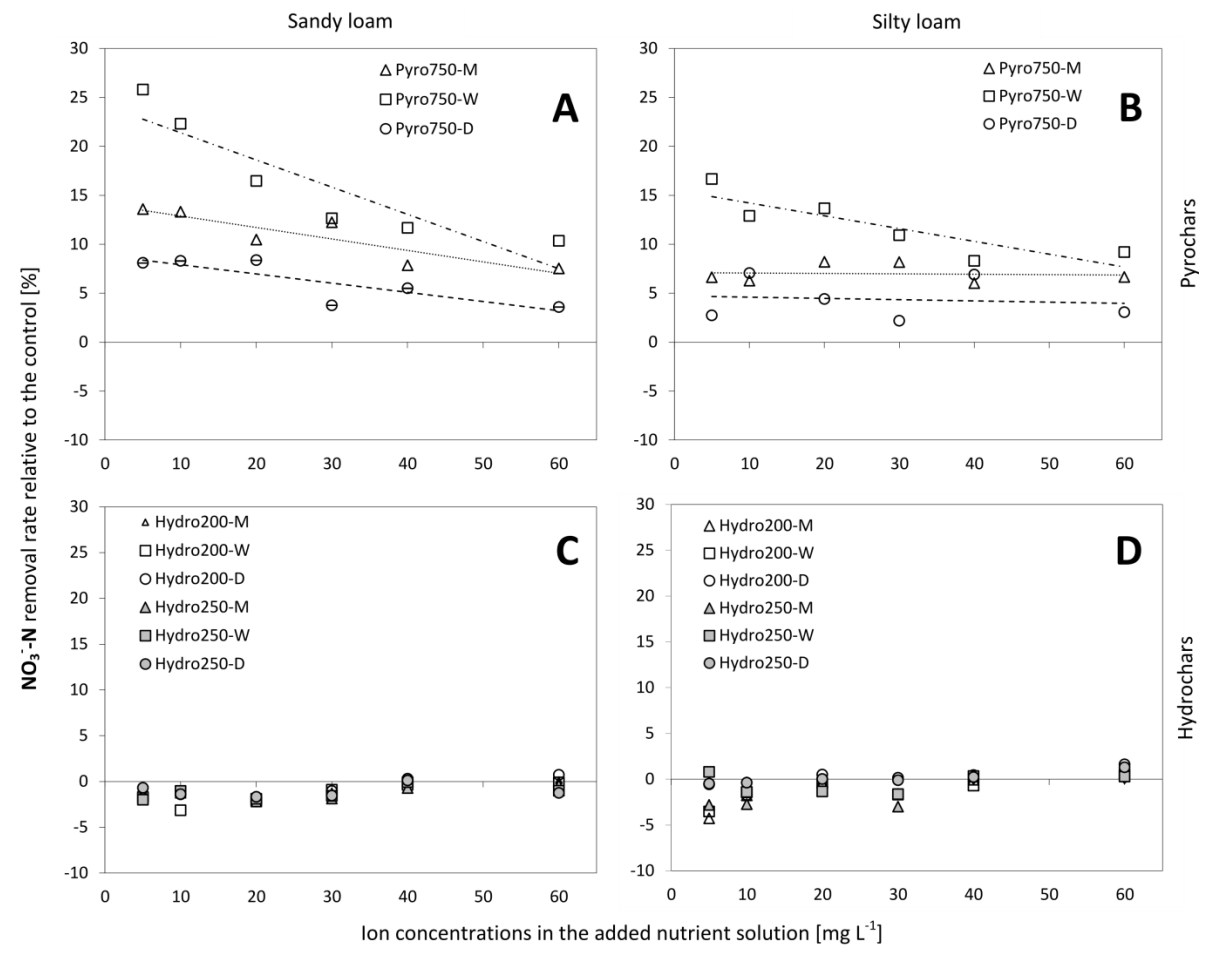

Figure 1. Mean $\mathrm{NO}_{3}^{-}-\mathrm{N}$ removal rates in soil-char composites relative to the control [\%] (the respective soil with no char added) for pyrochars (Pyro750) (a, b) and hydrochars derived at $200^{\circ} \mathrm{C}$ (Hydro200) and $250^{\circ} \mathrm{C}$ (Hydro250) (c, d) from Miscanthus (M), woodchips (W), and digestates (D) mixed with the sandy and silty loam soil at the six nutrient-solution levels $(n=3)$.

the respective control soil (Fig. 1a, b). The relative adsorption on Pyro750 decreased with increasing nutrient-solution concentration to $5-12 \%$. For both soil types, the fitted isotherms for Pyro750 were significantly different from the control $(p \leq 0.01)$ and to both Hydro200 and Hydro250 $(p \leq 0.01)$. Further, isotherms of $\mathrm{NO}_{3}^{-}$adsorption by Pyro750 mixed with sandy loam were significantly different to those of silt loam $(p \leq 0.01)$. Further, the effects of nutrient retention in Pyro750 mixtures compared to the control soil depended on the carbonized feedstock ( $p \leq 0.01$; Fig. 1a, b). Adsorption increased in the order digestates (3-8\%) < Miscanthus (10$14 \%) \leq$ woodchips (10-15\%) in both soil types depending on the nutrient-solution concentration. Addition of hydrochar to the soils had no effect on $\mathrm{NO}_{3}^{-}$adsorption irrespective of the carbonization temperature used, feedstock, or soil type (Fig. 1c, d).

\subsubsection{Sorption of ammonium}

The $\mathrm{NH}_{4}^{+}$sorption in the soils without char was around 3-4 times higher for the silty loam than the sandy loam (Table 3 ). The silty loam adsorbed around $55 \%$ at the first concentration level, and adsorption decreased to $32 \%$ with increasing nutrient concentrations, while the sandy loam adsorbed around $15 \%$ at all concentration levels.

Comparison of fitted isotherms of both soils mixed with Pyro750 showed significant differences between sandy loam and silty loam $(p \leq 0.01)$. The effect of feedstock on relative $\mathrm{NH}_{4}^{+}$adsorption was soil-dependent and significant for both soils (Fig. $2 \mathrm{a}, \mathrm{b} ; p \leq 0.05$ ). While $\mathrm{NH}_{4}^{+}$adsorption was enhanced by the application of pyrochar in the sandy loam, pyrochar addition to the silty loam showed no effect or even led to leaching. Further, the effect of the feedstock differed between the two soils investigated: when added to sandy loam, pyrochar application increased the adsorption relative to control. Depending on the nutrient solution concentration, the relative adsorption increased in the order Miscanthus $(\sim 0 \%)<$ woodchips $(2-8 \%)<$ digestate $(7-17 \%)(p \leq$ 0.01 ; Fig. 2a). For the silty loam, the effect of pyrochar addition on the relative $\mathrm{NH}_{4}^{+}$adsorption was woodchips $(\sim 0 \%)$ $<$ Miscanthus $(0-20 \%)<$ digestates (up to $-45 \%$ at the first two $\mathrm{NH}_{4}$ concentration levels; Fig. $2 \mathrm{~b}$ ) only at the first three nutrient concentration levels.

Application of hydrochars to either soil type showed no consistent effects. These ranged from leaching to adsorption with relative values between +10 and $-20 \%$, respectively (Fig. 2c, d). In general, $\mathrm{NH}_{4}^{+}$adsorption by the control soil was significantly different to that in the soil amended with hydrochars $(p \leq 0.01)$ for both sandy loam and silty loam. For Hydro200, $\mathrm{NH}_{4}^{+}$adsorption was close to zero when compared to the control at all concentration levels. A significant relative adsorption effect was observed for only some concentration points (Fig. 2c). Hydro250 showed both $\mathrm{NH}_{4}^{+}$re- 

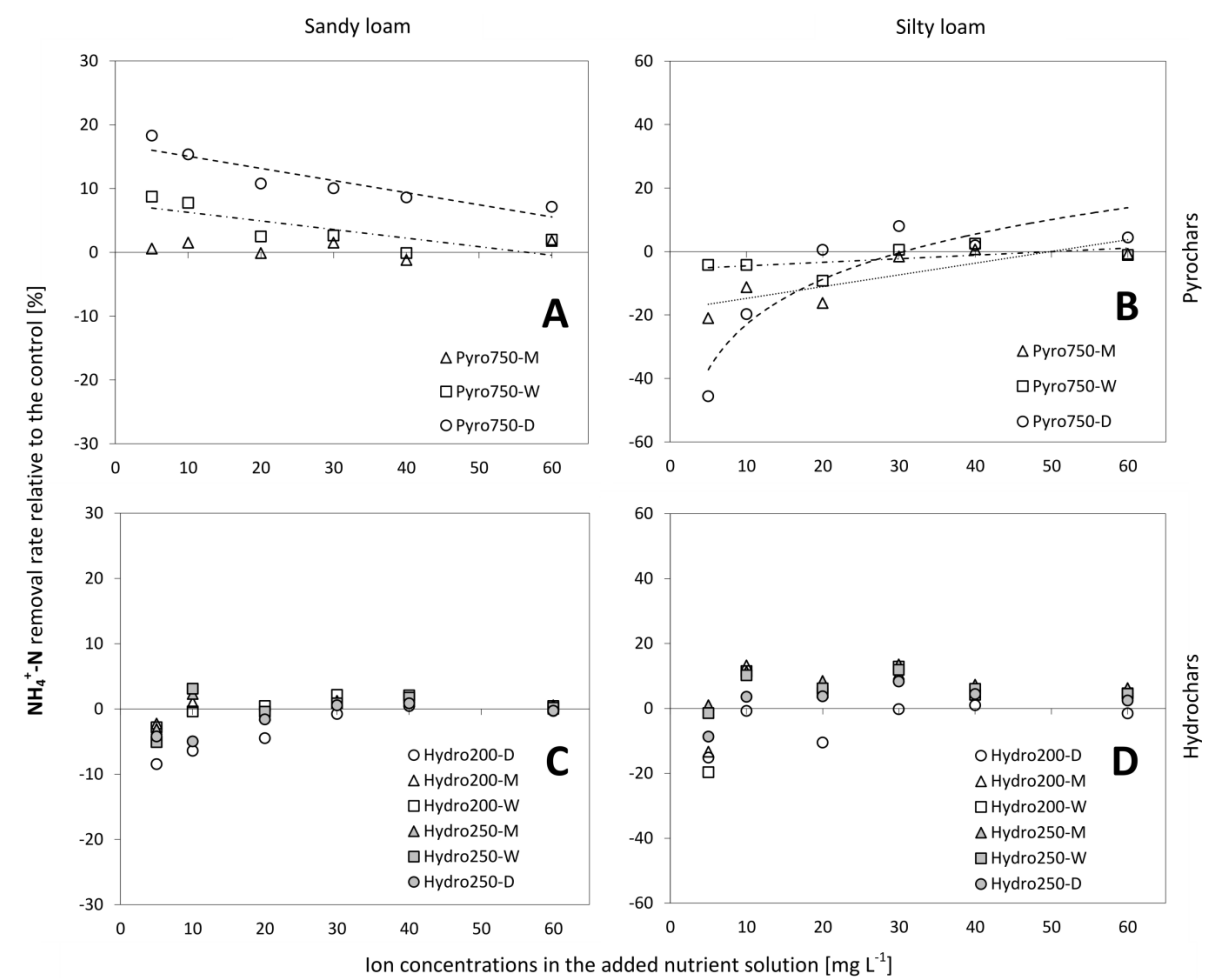

Figure 2. Mean $\mathrm{NH}_{4}^{+}-\mathrm{N}$ removal rates in soil-char composites relative to the control [\%] (the respective soil with no char added) for pyrochars (Pyro750) (a, b) and hydrochars derived at $200^{\circ} \mathrm{C}$ (Hydro200) and $250^{\circ} \mathrm{C}$ (Hydro250) (c, d) from Miscanthus (M), woodchips $(\mathrm{W})$, and digestates (D) mixed with the sandy and silty loam soil at the six nutrient-solution levels $(n=3)$.

lease at the lowest concentration level and little adsorption of $\mathrm{NH}_{4}^{+}$at the higher concentration levels reaching up to about $10 \%$ (Fig. 2d). The fitted isotherms for Pyro750 are significantly different from those for hydrochars and pure soil (depending on soil type), but there were no differences between Hydro200 and Hydro250. For hydrochars, no effect of feedstock on $\mathrm{NH}_{4}^{+}$adsorption was observed except for lower adsorption of Hydro200 from digestates compared to Miscanthus and woodchips $(p \leq 0.01)$.

\subsubsection{Sorption of phosphorus}

The sandy loam leached $\mathrm{PO}_{4}^{3-}$ at the lowest concentration level, but this changed to $65 \%$ adsorption at higher levels, while the silt loam adsorbed up to $80 \%$ at all $\mathrm{PO}_{4}^{3-}$ concentration levels (Fig. 3a, b).

Only pyrochars enhanced $\mathrm{PO}_{4}^{3-}$ adsorption. The fitted isotherms for pyrochars were significantly different from the respective control soil $(p \leq 0.01)$, but this effect strongly depended on feedstock material (digestates (only leaching) < Miscanthus < woodchips) and soil (silty loam < sandy loam). For Pyro750, there were significant $(p \leq 0.01)$ differences between feedstocks: Pyro750 from Miscanthus mixed with the sandy loam resulted in a relative $\mathrm{PO}_{4}^{3-}$ adsorption of 20-30\% (Fig. 3a) but 20\% less adsorption (leaching) when mixed with the silty loam (Fig. 3b). Woodchip pyrochar was most effective in adsorbing $\mathrm{PO}_{4}^{3-}$ (15-40\% for the silty loam and $60-70 \%$ for the sandy loam) during all nutrient-solution concentrations. However, pyrochar from digestates showed strong leaching in both sandy and silty loam (Fig. 3a, b). Adding Pyro750 from digestates enriched the nutrient solution by up to $1000 \%$ (sandy loam) and $1300 \%$ (silty loam) at the lowest $\mathrm{PO}_{4}^{3-}-\mathrm{P}$ concentration level, and still by $100 \%$ at the highest $\mathrm{PO}_{4}^{3-}-\mathrm{P}$ concentration. Although relative $\mathrm{PO}_{4}^{3-}$ adsorption was higher in the sandy loam than in the silty loam after addition of Pyro750, these differences were not significant.

The addition of hydrochar (both Hydro200 and Hydro250) to soil mainly led to leaching of $\mathrm{PO}_{4}^{3-}$ from chars or had no consistent effect (Fig. 3c, d). Fitted isotherms showed significant differences between Hydro200 and Pyro750 ( $p \leq 0.01)$ but no differences to control or Hydro250. The adsorption of the soil was lowered by maximum values of around $40 \%$ for the sandy loam and $60 \%$ for the silty loam due to $\mathrm{PO}_{4}^{3-}$ leaching. Values depended on the feedstock used and soil type $(p \leq 0.01)$. Again, the effect of feedstock (or any effect at all) was less pronounced for hydrochars than pyrochars: hydrochars from digestates tended to reduce the relative $\mathrm{PO}_{4}^{3-}$ adsorption by leaching. Mixing soil with Hydro200 and Hydro250 from Miscanthus and woodchips resulted in no effect on $\mathrm{PO}_{4}^{3-}$ adsorption (Fig. 3c). For both soil 


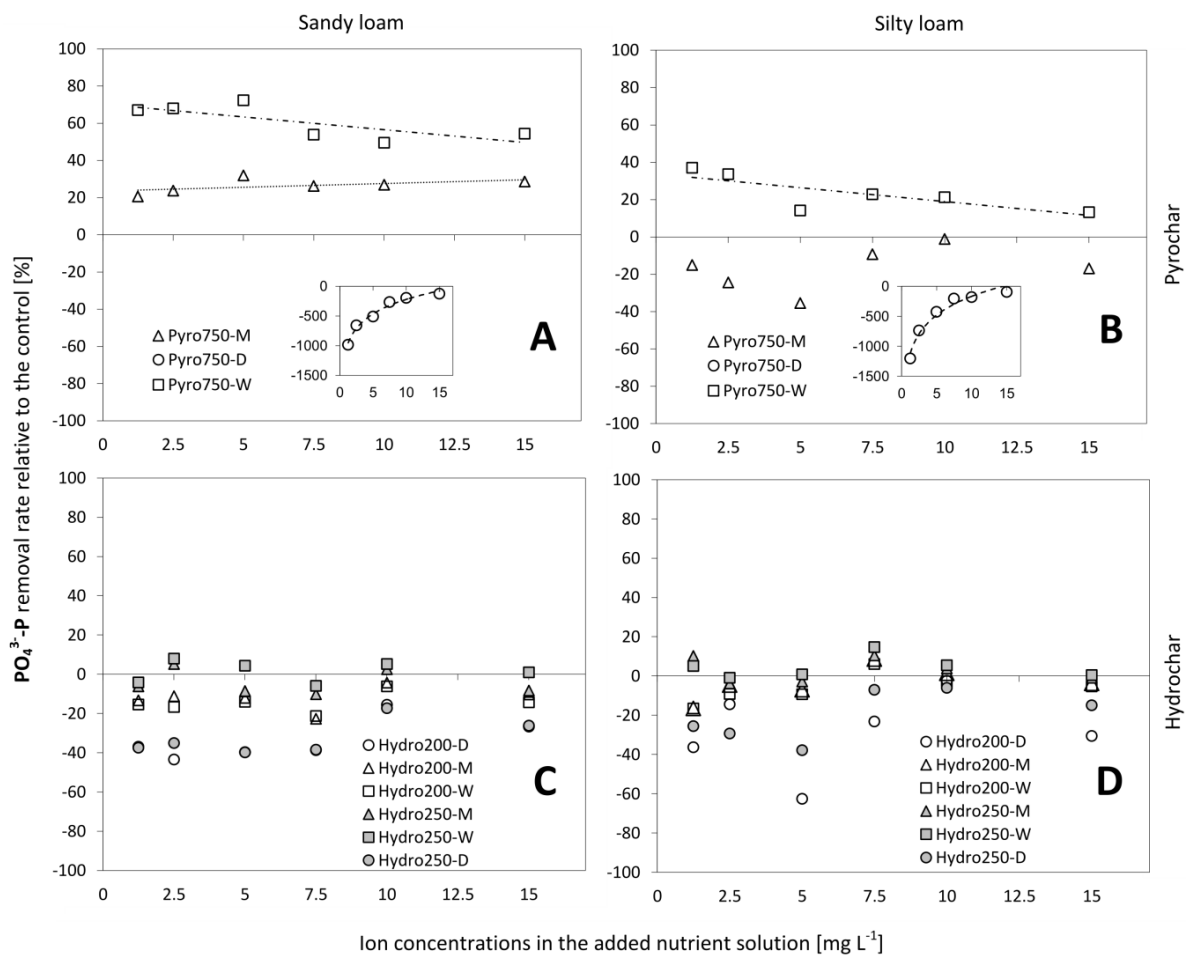

Figure 3. Mean $\mathrm{PO}_{4}^{3-}-\mathrm{P}$ removal rates in soil-char composites relative to the control [\%] (the respective soil with no char added) for pyrochars (Pyro750) (a, b) and hydrochars derived at $200^{\circ} \mathrm{C}$ (Hydro200) and $250^{\circ} \mathrm{C}$ (Hydro250) (c, d) from Miscanthus (M), woodchips (W), and digestates (D) mixed with the sandy and silty loam soil at the six nutrient-solution levels $(n=3)$.

types, differences between Hydro200 from digestates to Miscanthus and to woodchips were significant $(p \leq 0.01)$. For Hydro250, only digestates to Miscanthus and to woodchips were significantly different $(p \leq 0.01)$ in the sandy loam.

\subsection{The effect of char aging on nutrient sorption (field experiment)}

At all three experimental sites, $\mathrm{NO}_{3}^{-}$was leached from pure soil with no char addition (control; data not shown). However, leaching was less pronounced at $T_{1}$ than $T_{0}(p<0.01)$. Amending the soils with char led to adsorption of $\mathrm{NO}_{3}^{-}$ for both pyrochar and hydrochar at all experimental sites (Fig. 4a-c). However, adsorption was higher for pyrochars than hydrochars $(p \leq 0.01)$. Pyrochar reduced $\mathrm{NO}_{3}^{-}$leaching by up to $58 \%$ relative to the control soil at the lowest nutrient-solution concentration, while hydrochar reduced leaching by up to $25 \%$ (Fig. $4 \mathrm{a}-\mathrm{c}$ ). After 7 months of aging in the field $\left(T_{1}\right)$, adsorption by pyrochars decreased by 60 to $80 \%$, often ending up with no nutrient retention relative to control $(p<0.01$; Fig. $4 a-c)$. Slight differences were observed between the three investigated sites, but these were not significant. The effect of hydrochar addition diminished in a similar way after 7 months: relative adsorption decreased by 10 to $100 \%$, ending up with no nutrient retention at Bortfeld (Fig. 4a) or even nutrient leaching (site Querenhorst and site Volkmarsdorf, Fig. 4b, c), as compared to the nonamended control soil. In four of our six cases, sorption effects of both pyrochar and hydrochar were found to be significantly different for the aged biochar-soil mixture as compared to fresh biochars mixed into soils.

Highest adsorption of $\mathrm{NH}_{4}^{+}$was observed for fresh chars $\left(T_{0}\right)$ and adsorption was higher for pyrochar than for hydrochar at two sites (Bortfeld and Volkmarsdorf, $p \leq 0.01$ ) but was similar at the third site (Querenhorst) (Fig. 4d-f). For soils amended with fresh pyrochar, adsorption of $\mathrm{NH}_{4}^{+}$ was up to $40 \%$ higher than observed for the control soil. After 7 months, $\mathrm{NH}_{4}^{+}$adsorption of pyrochar-soil mixtures was significantly lower at all experimental sites than right after the char application $(p<0.01)$. Little relative $\mathrm{NH}_{4}^{+}$adsorption was found for fresh hydrochar and for aged hydrochar in the field. The relatively low adsorption capacity of hydrochars sometimes even changes to $\mathrm{NH}_{4}^{+}$leaching.

The effect of pyrochar aging on $\mathrm{PO}_{4}^{3-}$ adoption was different from the other nutrients: aging increased the $\mathrm{PO}_{4}^{3-}$ retention capacity of pyrochar soil mixtures at all three sites from leaching or no effect $\left(T_{0}\right)$ to adsorption $\left(T_{1}\right)$ (Fig. $4 \mathrm{~g}-\mathrm{i}$ ). The effect of hydrochar on $\mathrm{PO}_{4}^{3-}$ was minor. Hydrochar was a source for $\mathrm{PO}_{4}^{3-}$ in most soils with no consistent changes due to char aging. 

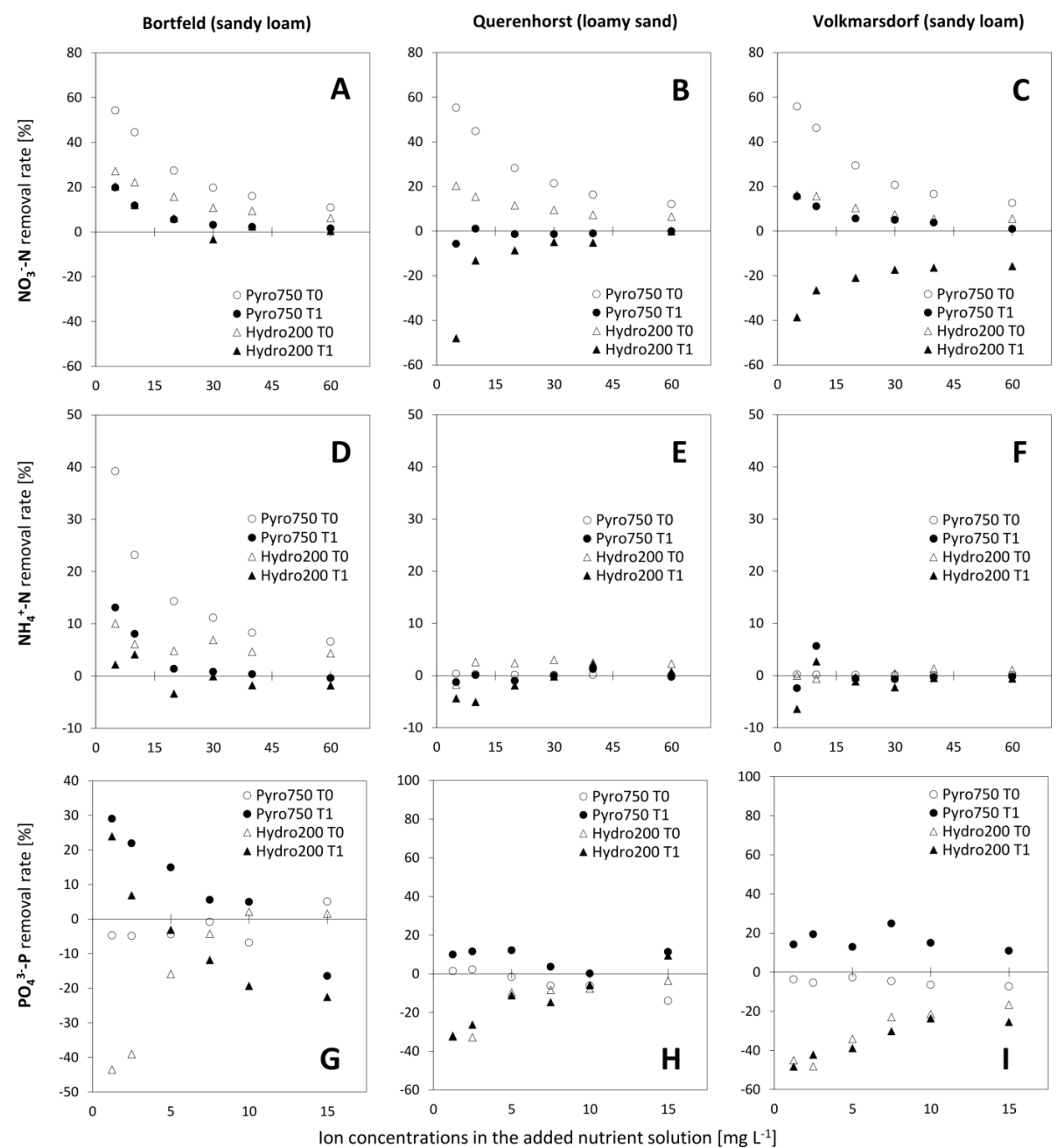

Figure 4. Mean $\mathrm{NO}_{3}^{-}-\mathrm{N}(\mathbf{a}-\mathbf{c}), \mathrm{NH}_{4}^{+}-\mathrm{N}(\mathbf{d}-\mathbf{f})$, and $\mathrm{PO}_{4}^{3-}-\mathrm{P}(\mathbf{g}-\mathbf{i})$ removal rate relative to the control for fresh $\left(T_{0}\right)$ and degraded $\left(T_{1}\right)$ pyrochars of the field experiment (for all treatments, $n=3$ ). Test statistics can be found in Tables S5, S7, and S8.

\subsection{Effects of char preparation (washing)}

Washing was carried out in order to reduce initial leaching effects from chars - i.e. it was assumed that nutrients and salts were removed from the surface of the chars by washing. Figure 5 shows relative changes in ion concentration to control $\left(0 \%\right.$ line; $\mathrm{IC}_{\text {Blind }}: 20.23 \mathrm{mg} \mathrm{N} \mathrm{L}^{-1}$; $\mathrm{IC}_{\mathrm{Ctrl}}$ : $23.37 \mathrm{mg} \mathrm{N} \mathrm{L}^{-1}$ ) at nutrient concentration level P3 (Table 3). Positive (negative) values indicate higher (lower) removal of ions from nutrient solution compared to control due to adsorption or leaching, respectively. Washing of both Hydro200 and Hydro250 increased the $\mathrm{pH}$ of the nutrient solution by 0.1 to $0.2 \mathrm{pH}$ units, whereas washing of Pyro750 decreased the $\mathrm{pH}$ by 0.2 to 0.4 units. The sorption behavior of both pyrochars and hydrochars significantly changed due to washing (Fig. 5). Washing increased the potential $\mathrm{NO}_{3}^{-}$adsorption of pyrochars by $3-4 \%$ ( $p \leq 0.05$; Fig. 5a). For hydrochars, a similar effect was only observed for Hydro200 from digestates, changing the soil-hydrochar mix- ture from a $\mathrm{NO}_{3}^{-}$source (leaching) into a sink (absorption) $(p \leq 0.05)$. In the case of $\mathrm{NH}_{4}^{+}$, a decrease in net leaching was observed for all treatments (Fig. 5b). For most hydrochars, washing even turned soil-hydrochar mixtures from $\mathrm{NH}_{4}^{+}$sources (leaching) into net sinks (adsorption) (Fig. 5b). Strongest reductions in leaching were observed for Pyro750 $(-37 \%)$ and Hydro200 from digestates $(-35 \%)$. Washing effects on $\mathrm{PO}_{4}^{3-}$ sorption were inconsistent. Pyro750 showed increased $\mathrm{PO}_{4}^{3-}$ leaching (digestates), decreased adsorption (woodchips), and leaching instead of sorption (Miscanthus) (Fig. 5c). In the case of Hydro200 from digestates, $\mathrm{PO}_{4}^{3-}$ leaching was reduced by up to $-950 \%$. For all other hydrochar mixtures, washing reduced both $\mathrm{PO}_{4}^{3-}$ leaching and sorption close to zero. Overall, washing seemed to be an effective measure to reduce the ion leaching of those ions that were adsorbed to the surface of fresh chars. 

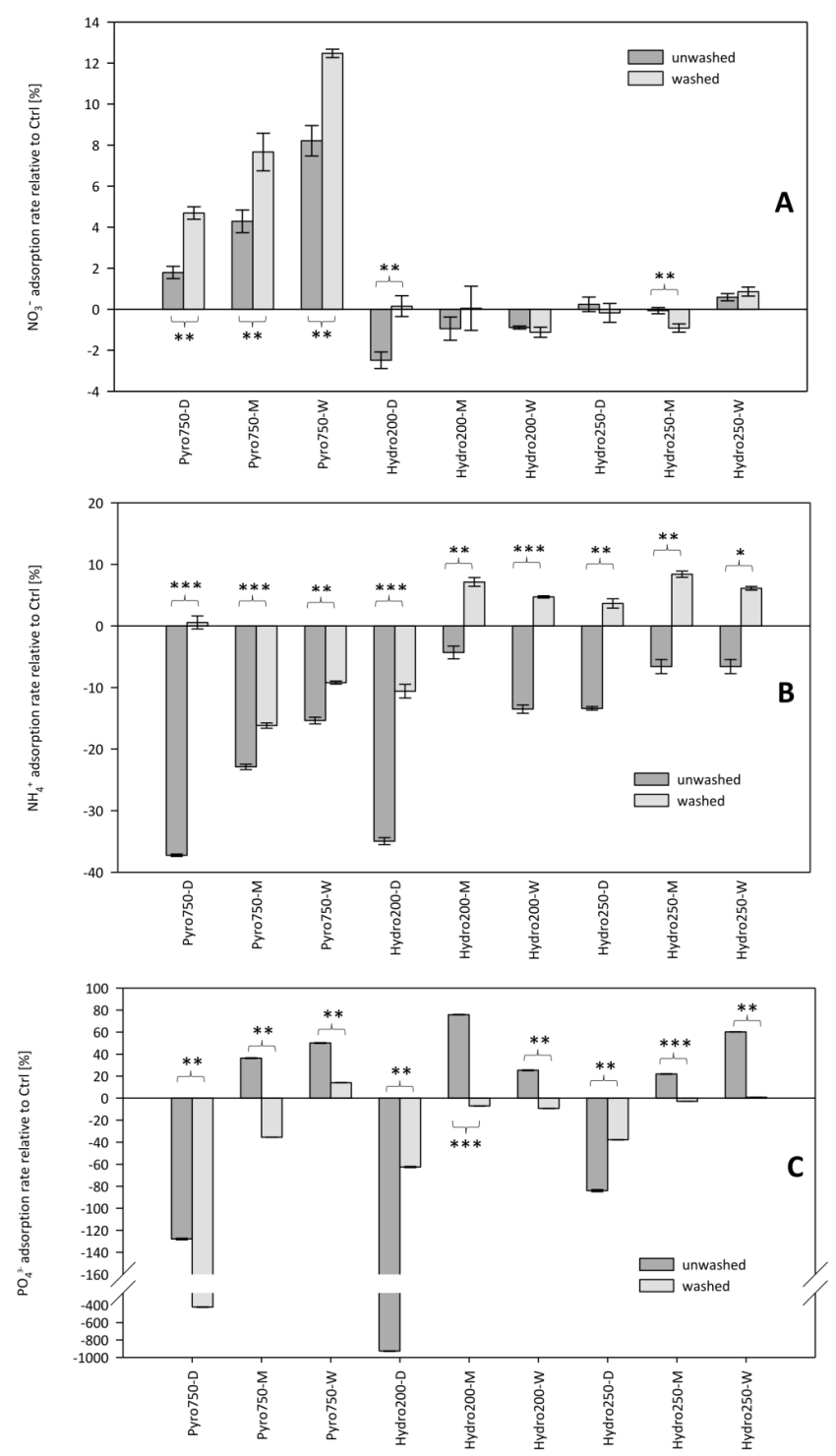

Figure 5. (a) $\mathrm{NO}_{3}^{-}$, (b) $\mathrm{NH}_{4}^{+}$, and (c) $\mathrm{PO}_{4}^{3-}$ removal rates in soilchar composites relative to the control (silt loam without char) for washed and unwashed pyrochars (Pyro750) and hydrochars derived at $200{ }^{\circ} \mathrm{C}$ (Hydro200) and $250^{\circ} \mathrm{C}$ (Hydro250) from Miscanthus (M), woodchips (W), and digestates (D). Significant differences between washed and unwashed chars were tested with the unpaired $t$ test. $p$ values are indicating by $* * *<0.01, * *<0.05$, and $*<0.1$ (for each treatment $n=3$, means $\pm \mathrm{SE}$ ).

\section{Discussion}

\subsection{Char-induced effects on nutrient sorption: effects of carbonization process and feedstock material (laboratory experiments)}

Pyrochars and hydrochars showed general differences in their sorption behavior. In most cases, pyrochars removed $\mathrm{NO}_{3}^{-}, \mathrm{NH}_{4}^{+}$, and $\mathrm{PO}_{4}^{3-}$ from soil solution. This is in line with previous studies (Hale et al., 2013; Sarkhot et al., 2013;
Yao et al., 2012). Hydrochars showed marginal or no sorptive effect on $\mathrm{NO}_{3}^{-}, \mathrm{NH}_{4}^{+}$, and $\mathrm{PO}_{4}^{3-}$. Similar to our findings, Yao et al. (2012) found no sorptive effect of hydrochar from peanut hulls on $\mathrm{NO}_{3}^{-}, \mathrm{NH}_{4}^{+}$, and $\mathrm{PO}_{4}^{3-}$. Previous studies indicate that increasing carbonization temperature results in higher SSA of the produced char (Cantrell et al., 2012), which in turn leads to higher $\mathrm{NO}_{3}^{-}$adsorption (Hale et al., 2013; Lehmann and Joseph, 2009; Yao et al., 2012). However, the AIC was used to select the best-fitting isothermal model. For $\mathrm{NO}_{3}^{-}$sorption on pyrochars, AIC prefers the fitted linear model rather than the Freundlich isotherm, which indicates a non-saturated surface of chars at increasing ion concentration of the nutrient solution. This contradicts previous studies which prefer Freundlich or Langmuir (Hale et al., 2013; Mizuta et al., 2004). In most cases, hydrochars showed no sorptive effect, but, in particular for hydrochars from digestates, $\mathrm{PO}_{4}^{3-}$ release into aqueous solution was partly observed. This finding is corroborated by Yao et al. (2012), who also found $4 \% \mathrm{PO}_{4}^{3-}$ leaching into aqueous solution in sandy soil mixed with hydrochar from peanut hull. The digestate feedstock and digestate carbonized to pyrochar and hydrochar contained 10 times more phosphorus $(2.51 \%$, Table 1) than the chars produced from the other two feedstock materials, which explains the high $\mathrm{PO}_{4}^{3-}$ leaching.

Besides carbonization process, the feedstock material had a marked influence on the sorption behavior, which is in accordance with findings from other studies: while $\mathrm{NO}_{3}^{-}$ sorption was observed for pyrochar from Monterey pine (Knowles et al., 2011), sugarcane bagasse, and bamboo (Mizuta et al., 2004; Yao et al., 2012), pyrochar from pure washed cacao shell and corn cob without soil led to $\mathrm{NO}_{3}^{-}$ release (Hale et al., 2013). This implies strong adsorption capacity variations with carbonized feedstock. The three carbonized feedstocks we tested (Miscanthus, digestates, and woodchips) for pyrochars showed high correlations between $\mathrm{NO}_{3}^{-}$adsorption and logarithmized SSA $\left(R^{2}=0.57\right.$; $p \leq 0.05$ for amended loamy soil/ $0.64 ; p \leq 0.01$ amended sandy soil), and average pore size $\left(R^{2}=0.64\right.$ for amended loamy soil/ $/ 0.72$ for amended sandy soil; both $p \leq 0.01)$. We also found strong correlations between $\mathrm{H}: \mathrm{C}$ (indicates carbonization temperature) and $\mathrm{NO}_{3}^{-}$adsorption $\left(R^{2}=0.65\right.$ for amended loamy/0.75 sandy soil respectively; both $p \leq 0.01$ ). The $\mathrm{NH}_{4}^{+}$sorption is strongly nonlinear with increasing solution concentration (Freundlich coefficient $n=1.1-1.5$ ), which indicates a limited number of cation exchange sites of char (Hale et al., 2013). For all pyrochars, irrespective of feedstock, pore volume $\left(R^{2}=0.52, p \leq 0.01\right)$, and ash content $\left(R^{2}=0.66, p \leq 0.01\right)$ correlated with $\mathrm{NH}_{4}^{+}$adsorption. No saturation was found for $\mathrm{PO}_{4}^{3-}$, with increasing solution concentration, especially evident for pyrochars from Miscanthus and also from woodchips for the concentration range used $\left(2.5-15 \mathrm{mg} \mathrm{PL}^{-1}\right)$. This indicates that pyrochars could remove more $\mathrm{PO}_{4}^{3-}$ at higher solution concentrations, which is supported by Sarkhot et al. (2013), who tested $2 \mathrm{~g}$ of 
pyrolyzed hardwood chars (without soil) in $40 \mathrm{~mL}$ of nutrient solution at higher solution concentrations in comparison to ours (up to $50 \mathrm{mg} \mathrm{PL}^{-1}$ ).

Generally, nutrient retention potential of char is a result of cation or anion exchange combined with the large surface area, internal porosity and polar and nonpolar surface sites of functional groups (Hale et al., 2013; Laird et al., 2010; Lehmann and Joseph, 2009). Additionally, Keiluweit and Kleber (2009) reviewed cyclic aromatic $\pi$ systems which showed specific $\pi$-electron donor-acceptor (EDA) interactions (i.e., cation $-\pi$, hydrogen $-\pi, \pi-\pi$ EDA, and polar $-\pi$ interaction) with bonding energies between 4 and $167 \mathrm{~kJ} \mathrm{~mol}^{-1}$ to nutrients. Thus, chars' surface charge is assumed to be negative, resulting in low anion exchange capacity and repellence of $\mathrm{NO}_{3}^{-}$and $\mathrm{PO}_{4}^{3-}$ (Hale et al., 2013; Mukherjee et al., 2011). However, our results and results from previous studies showed anion adsorption, the processes of which are not yet fully understood. Chun et al. (2004) and Chen et al. (2008) disproved the ability of $\mathrm{PO}_{4}^{3-}$ ions to bind with negatively charged char surface functional groups like hydroxyls, carbonyls, carboxyls, and phenolics. However, Sarkhot et al. (2013) proposed that the exchange of surface hydroxyl groups on biochar with $\mathrm{PO}_{4}^{3-}$ induces a $\mathrm{pH}$-controlled anion sorption capacity. Another mechanism is the ability of $\mathrm{PO}_{4}^{3-}$ ions to form bridge bonds using the residual charge of electrostatically attracted or ligand-bonded multivalent cations $\left(\mathrm{Ca}^{2+}, \mathrm{Mg}^{2+}, \mathrm{Al}^{3+}\right.$, $\mathrm{Fe}^{3+}$ ) (Mukherjee et al., 2011). We could not directly verify this assumption in our study because $\mathrm{Ca}^{2+}$ and $\mathrm{Mg}^{2+}$ were strongly leached (see Supplement; Table S1), but we suspect that the residual charge of electrostatically attracted cations binds $\mathrm{PO}_{4}^{3-}$ in the double-layer sheet. Klasson et al. (2014) showed that pore-blocking ash content could be reduced by washing chars with rainwater, thereby increasing micropore volume, total pore volume, and SSA. Hale et al. (2013) suggest enhanced $\mathrm{PO}_{4}^{3-}$ sorption due to increasing availability of binding sites on char's surface after washing. However, in our lab experiment we did not find increasing $\mathrm{PO}_{4}^{3-}$ adsorption due to washing for any type of char. We assume that primary bonding agents for $\mathrm{PO}_{4}^{3-}\left(\mathrm{Ca}^{2+}, \mathrm{Mg}^{2+}, \mathrm{Al}^{3+}, \mathrm{Fe}^{3+}\right)$ are leached out, which results in no adsorption to the char surface. Secondly, $\mathrm{PO}_{4}^{3-}$ compounds from the char matrix itself are rinsed.

\subsection{Soil-induced effect on nutrient sorption (laboratory experiments)}

Our results show that pyrochars could remove $\mathrm{NO}_{3}^{-}$and $\mathrm{PO}_{4}^{3-}$ from soil solution when added to different soils (sandy and silty loam). $\mathrm{NH}_{4}^{+}$was retained only in the sandy loam which confirms the findings of Yao et al. (2012), who also mixed pyrochars with a sandy soil. For pyrochars mixed with loamy soil, we found reduced sorption capacity for $\mathrm{NO}_{3}^{-}$, $\mathrm{NH}_{4}^{+}$, and $\mathrm{PO}_{4}^{3-}$, which is corroborated by Hale et al. (2011), who reported a reduction in the sorption capacity of chars mixed with a fine-loamy soil. Hydrochars showed little (silty loam) or no (sandy loam) sorptive effect on $\mathrm{NO}_{3}^{-}, \mathrm{NH}_{4}^{+}$, and $\mathrm{PO}_{4}^{3-}$.

The adsorption capacity of chars for nutrients interacts with the amended soil type. Generally, soil's adsorption capacity for $\mathrm{NO}_{3}^{-}, \mathrm{NH}_{4}^{+}$, and $\mathrm{PO}_{4}^{3-}$ is determined by $\mathrm{pH}, \mathrm{CEC}$, AEC, SSA, organic matter content, and soil texture. Hale et al. (2011) suggest a decreased reduction in the sorption capacity of chars caused by blocking of sorption sites by DOC, which could leach out from soil and may adsorb to chars. The solubility of DOC can be increased by increasing negative charge on the DOC due to a raised $\mathrm{pH}$ through char application to soils (Alling et al., 2014). In our study, application of pyrochars led to a stronger rise in $\mathrm{pH}$ in the silty loam than in the sandy loam (Table S2). According to Hale et al. (2011), this could have induced higher DOC solubility in the sandy loam and the leached DOC was adsorbed by pyrochars, resulting in blocked binding sites. Further, the soils tested in this study differed strongly in their texture and CEC. The silty loam contained higher amounts of multi-layer clay minerals, which led to higher adsorption competition between char and clay mineral surfaces. Ersahin et al. (2006) report SSA between 46.5 and 90.38 as well as 20.60 and $61.95 \mathrm{~m}^{2} \mathrm{~g}^{-1}$ for silty loams and loamy sands, respectively. The pyrochars we tested had SSAs between 210 and $448 \mathrm{~m}^{2} \mathrm{~g}^{-1}$, which are considerably higher than the SSA of the soils used. The difference in SSA between pyrochar and soil was larger for the sandy loam than the silty loam. This resulted in stronger adsorption potential for ions from sandy loam or nutrient solution to the pyrochars. However, the larger SSA of the silty loam enhanced the adsorption competition for ions between loamy sand and pyrochars. In addition, ions from the nutrient solution are more attracted to the silty loam than to the sandy loam or to the pyrochars. Furthermore, soil-bound ions such as $\mathrm{NO}_{3}^{-}, \mathrm{K}^{+}, \mathrm{Mg}^{2+}$, and $\mathrm{Ca}^{2+}$ were leached from the silty loam and were directly adsorbed by pyrochars, suggesting that this direct adsorption may result in occupied binding sites on the pyrochars, which led to no or less adsorption of $\mathrm{NO}_{3}^{-}, \mathrm{NH}_{4}^{+}$and $\mathrm{PO}_{4}^{3-}$ from the nutrient solution.

\subsection{Effect of char aging on nutrient sorption (field and laboratory experiment)}

The ability of both pyrochar and hydrochar to adsorb $\mathrm{NO}_{3}^{-}$ and $\mathrm{NH}_{4}^{+}$from soil solution was stronger for fresh char as compared to aged char (i.e., after 7 months of field incubation). This was an unexpected behavior and often led to a complete loss of the char's nutrient retention capacity and has rarely been studied to date. Since the overall adsorption capacity of hydrochar observed in our study was small, the aging effect was also less pronounced compared to pyrochars. For hydrochars, other studies reported the physical 
structure and chemical properties result in a lower recalcitrance towards microbial degradation compared to pyrochars (Bargmann et al., 2014a; Hale et al., 2011; Steinbeiss et al., 2009). Explanations for the decreasing nitrogen adsorption capacity of pyrochar may include the following: (a) binding sites of both types of char may be blocked with organic matter or mineral particles such as clay, and (b) binding sites of pyrochar may be reduced by microbial degradation changing the char's surface properties, which in turn leads to a diminished number of negatively charged binding sites (Cheng et al., 2008, 2006; Glaser et al., 2000). However, for our study, we could not explain decreasing adsorption with these mechanisms.

Such a trend of decreasing adsorption capacity over time was also reported by Bargmann et al. (2014b), who incubated 2 and $4 \%$ hydrochars from beetroot chips (Beta vulgaris) with a loamy soil for 8 weeks in the laboratory. A diminished number of negatively charged binding sites may result in higher leaching of positively charged ions (such as $\mathrm{NH}_{4}^{+}, \mathrm{Ca}^{2+}, \mathrm{Mg}^{2+}$, and $\mathrm{K}^{+}$). In our experiment, the adsorption rate of $\mathrm{NH}_{4}^{+}$was reduced over time and $\mathrm{Ca}^{2+}$ as well as $\mathrm{Mg}^{2+}$ showed higher leaching after 7 months (Table S5). The chars used in the field experiment had not been pretreated by washing. The increased adsorption capacity of char for $\mathrm{PO}_{4}^{3-}$ may thus be partly a result of initially bound $\mathrm{PO}_{4}^{3-}$ that was leached from fresh chars $\left(T_{0}\right)$ and was leached less after 7 months $\left(T_{1}\right)$. However, in our laboratory experiment, washing did not reduce $\mathrm{PO}_{4}^{3-}$ leaching but increased the adsorption. Phosphate adsorption on char depends strongly on $\mathrm{pH}$. For the chars we used, the effect on $\mathrm{pH}$ in the nutrient solution was lower for washed than unwashed chars.

\section{Conclusions}

The nutrient retention potential of chars (i.e., nitrate, ammonium, and phosphate) differs strongly with nutrient, char type (hydrochar vs. pyrochar), and type of carbonized feedstock, as well as amended soil type. Among nine different types of chars tested in a laboratory batch experiment, only pyrochars showed the ability to effectively retain nitrate, ammonium, and phosphate. Moreover, the nutrient retention effect seems to be of very limited duration. After 7 months in the field, around 60 to $80 \%$ of the adsorption capacity of pyrochar was lost. Underlying mechanisms are poorly understood, but our results cast doubt on the efficiency of char application to minimize the problems of nutrient leaching from agricultural soils to the groundwater and adjacent ecosystems.

\section{The Supplement related to this article is available online at doi:10.5194/soil-1-475-2015-supplement.}

Acknowledgements. This project was financed by the German Research Foundation (DFG - Research Training Group 1397 "Regulation of soil organic matter and nutrient turnover in organic agriculture", University of Kassel, Witzenhausen). The authors want to thank Claudia Wiese and Andrea Niemeyer for laboratory analyses, as well as Roland Fuß for statistical support.

Edited by: C. Rumpel

\section{References}

Abel, S., Peters, A., Trinks, S., Schonsky, H., Facklam, M., and Wessolek, G.: Impact of biochar and hydrochar addition on water retention and water repellence of sandy soil, Geoderma, 202203, 183-191, doi:10.1016/j.geoderma.2013.03.003, 2013.

Alling, V., Hale, S. E., Martinsen, V., Mulder, J., Smebye, A., Breedveld, G. D., and Cornelissen, G.: The role of biochar in retaining nutrients in amended tropical soils, J. Plant Nutr. Soil Sc., 177, 671-680, 2014.

Bandosz, T. J. and Petit, C.: On the reactive adsorption of ammonia on activated carbons modified by impregnation with inorganic compounds, J. Colloid Interf. Sci., 338, 329-345, 2009.

Bargmann, I., Martens, R., Rillig, M. C., Kruse, A., and Kucke, M.: Hydrochar amendment promotes microbial immobilization of mineral nitrogen, J. Plant Nutr. Soil Sc., 177, 59-67, 2014a.

Bargmann, I., Rillig, M. C., Kruse, A., Greef, J. M., and Kucke, M.: Effects of hydrochar application on the dynamics of soluble nitrogen in soils and on plant availability, J. Plant Nutr. Soil Sc., 177, 48-58, 2014b.

Benjamini, Y. and Hochberg, Y.: Controlling the false discovery rate - a practical and powerful approach to multiple testing, J. R. Stat. Soc. B. Met., 57, 289-300, 1995.

Blagodatskaya, E., Blagodatsky, S., Anderson, T. H., and Kuzyakov, Y.: Microbial growth and carbon use efficiency in the rhizosphere and root-free soil, PloS one, 9, e93282, doi:10.1371/journal.pone.0093282, 2014.

Cantrell, K. B., Hunt, P. G., Uchimiya, M., Novak, J. M., and Ro, K. S.: Impact of pyrolysis temperature and manure source on physicochemical characteristics of biochar, Bioresource Technol., 107, 419-428, 2012.

Cao, X. Y., Ro, K. S., Chappell, M., Li, Y. A., and Mao, J. D.: Chemical Structures of Swine-Manure Chars Produced under Different Carbonization Conditions Investigated by Advanced SolidState C-13 Nuclear Magnetic Resonance (NMR) Spectroscopy, Energy Fuels, 25, 388-397, 2011.

Castaldi, S., Riondino, M., Baronti, S., Esposito, F. R., Marzaioli, R., Rutigliano, F. A., Vaccari, F. P., and Miglietta, F.: Impact of biochar application to a Mediterranean wheat crop on soil microbial activity and greenhouse gas fluxes, Chemosphere, 85, 1464 1471, 2011.

Chen, B. L. and Yuan, M. X.: Enhanced sorption of polycyclic aromatic hydrocarbons by soil amended with biochar, J. Soil. Sediment., 11, 62-71, doi:10.1007/s11368-010-0266-7, 2011.

Chen, B. L., Zhou, D. D., and Zhu, L. Z.: Transitional adsorption and partition of nonpolar and polar aromatic contaminants by biochars of pine needles with different pyrolytic temperatures, Environ. Sci. Technol., 42, 5137-5143, 2008. 
Cheng, C.-H., Lehmann, J., Thies, J. E., Burton, S. D., and Engelhard, M. H.: Oxidation of black carbon by biotic and abiotic processes, Org. Geochem., 37, 1477-1488, 2006.

Cheng, C.-H., Lehmann, J., and Engelhard, M. H.: Natural oxidation of black carbon in soils: Changes in molecular form and surface charge along a climosequence, Geochim. Cosmochim. Ac., 72, 1598-1610, 2008.

Chun, Y., Sheng, G. Y., Chiou, C. T., and Xing, B. S.: Compositions and sorptive properties of crop residue-derived chars, Environ. Sci. Technol., 38, 4649-4655, 2004.

Ding, Y., Liu, Y.-X., Wu, W.-X., Shi, D.-Z., Yang, M., and Zhong, Z.-K.: Evaluation of Biochar Effects on Nitrogen Retention and Leaching in Multi-Layered Soil Columns N, Water Air Soil Poll., 213, 47-55, 2010.

Eibisch, N., Helfrich, M., Don, A., Mikutta, R., Kruse, A., Ellerbrock, R., and Flessa, H.: Properties and degradability of hydrothermal carbonization products, J. Environ. Qual., 42, 15651573, 2013.

Eibisch, N., Schroll, R., Fuß, R., Mikutta, R., Helfrich, M., and Flessa, H.: Pyrochars and hydrochars differently alter the sorption of the herbicide isoproturon in an agricultural soil, Chemosphere, 119, 155-162, 2015.

Ersahin, S., Gunal, H., Kutlu, T., Yetgin, B., and Coban, S.: Estimating specific surface area and cation exchange capacity in soils using fractal dimension of particle-size distribution, Geoderma, 136, 588-597, 2006.

Funke, A. and Ziegler, F.: Hydrothermal carbonization of biomass: A summary and discussion of chemical mechanisms for process engineering, Biofuels Bioprod. Biorefin., 4, 160-177, 2010.

Glaser, B., Balashov, E., Haumaier, L., Guggenberger, G., and Zech, W.: Black carbon in density fractions of anthropogenic soils of the Brazilian Amazon region, Org. Geochem., 31, 669-678, 2000.

Glaser, B., Lehmann, J., and Zech, W.: Ameliorating physical and chemical properties of highly weathered soils in the tropics with charcoal - a review, Biol. Fertil. Soils, 35, 219-230, 2002.

Hale, S. E., Hanley, K., Lehmann, J., Zimmerman, A., and Cornelissen, G.: Effects of chemical, biological, and physical aging as well as soil addition on the sorption of pyrene to activated carbon and biochar, Environ. Sci. Technol., 45, 10445-10453, 2011.

Hale, S. E., Alling, V., Martinsen, V., Mulder, J., Breedveld, G. D., and Cornelissen, G.: The sorption and desorption of phosphate-P, ammonium- $\mathrm{N}$ and nitrate- $\mathrm{N}$ in cacao shell and corn cob biochars, Chemosphere, 91, 1612-1619, 2013.

Hastie, T.: gam: Generalized Additive Models, R package version 1.09.1., available at: http://CRAN.R-project.org/package=gam (last access: August 2014), 2013.

Jones, D. L., Rousk, J., Edwards-Jones, G., DeLuca, T. H., and Murphy, D. V.: Biochar-mediated changes in soil quality and plant growth in a three year field trial, Soil Biol. Biochem., 45, 113124, 2012.

Karaca, S., Gurses, A., Ejder, M., and Acikyildiz, M.: Kinetic modeling of liquid-phase adsorption of phosphate on dolomite, J. Colloid interf. Sci., 277, 257-263, 2004.

Keiluweit, M. and Kleber, M.: Molecular-Level Interactions in Soils and Sediments: The Role of Aromatic pi-Systems, Environ. Sci. Technol., 43, 3421-3429, 2009.
Keiluweit, M., Nico, P. S., Johnson, M. G., and Kleber, M.: Dynamic Molecular Structure of Plant Biomass-Derived Black Carbon (Biochar), Environ. Sci. Technol., 44, 1247-1253, 2010.

Klasson, K. T., Uchimiya, M., and Lima, I. M.: Uncovering surface area and micropores in almond shell biochars by rainwater wash, Chemosphere, 111, 129-134, 2014.

Knowles, O. A., Robinson, B. H., Contangelo, A., and Clucas, L.: Biochar for the mitigation of nitrate leaching from soil amended with biosolids, Sci. Total Environ., 409, 3206-3210, 2011.

Laird, D., Fleming, P., Wang, B., Horton, R., and Karlen, D.: Biochar impact on nutrient leaching from a Midwestern agricultural soil, Geoderma, 158, 436-442, 2010.

Lehmann, J. and Joseph, S.: Biochar for environmental management: science and technology, Earthscan, London; Sterling, VA, 2009.

Lehmann, J., da Silva, J. P., Steiner, C., Nehls, T., Zech, W., and Glaser, B.: Nutrient availability and leaching in an archaeological Anthrosol and a Ferralsol of the Central Amazon basin: fertilizer, manure and charcoal amendments, Plant Soil, 249, 343357, 2003.

Lehmann, J., Gaunt, J., and Rondon, M.: Bio-char sequestration in terrestrial ecosystems - a review, Mitig. Adapt. Strat. Gl., 11, 403-427, 2006.

Lehmann, J., Rillig, M. C., Thies, J., Masiello, C. A., Hockaday, W. C., and Crowley, D.: Biochar effects on soil biota - A review, Soil Biol. Biochem., 43, 1812-1836, 2011.

Liang, B., Lehmann, J., Solomon, D., Kinyangi, J., Grossman, J., O’Neill, B., Skjemstad, J. O., Thies, J., Luizão, F. J., Petersen, J., and Neves, E. G.: Black Carbon Increases Cation Exchange Capacity in Soils, Soil Sci. Soc. Am. J., 70, 1719-1730, doi:10.2136/sssaj2005.0383, 2006.

Libra, J. A., Ro, K. S., Kammann, C., Funke, A., Berge, N. D., Neubauer, Y., Titirici, M. M., Fuhner, C., Bens, O., Kern, J., and Emmerich, K. H.: Hydrothermal carbonization of biomass residuals: a comparative review of the chemistry, processes and applications of wet and dry pyrolysis, Biofuels, 2, 71-106, 2011.

Liu, Z., Demisie, W., and Zhang, M.: Simulated degradation of biochar and its potential environmental implications, Environ. Pollut., 179, 146-152, 2013.

Mizuta, K., Matsumoto, T., Hatate, Y., Nishihara, K., and Nakanishi, T.: Removal of nitrate-nitrogen from drinking water using bamboo powder charcoal, Bioresource Technol., 95, 255-257, 2004.

Morales, M. M., Comerford, N., Guerrini, I. A., Falcão, N. P. S., and Reeves, J. B.: Sorption and desorption of phosphate on biochar and biochar-soil mixtures, Soil Use Manage., 29, 306-314, 2013.

Mukherjee, A., Zimmerman, A. R., and Harris, W.: Surface chemistry variations among a series of laboratory-produced biochars, Geoderma, 163, 247-255, 2011.

R Core Team: R: A language and environment for statistical computing, R Foundation for Statistical Computing, Vienna, Austria, 2014.

Sarkhot, D. V., Berhe, A. A., and Ghezzehei, T. A.: Impact of Biochar Enriched with Dairy Manure Effluent on Carbon and Nitrogen Dynamics, J. Environ. Qual., 41, 1107-1114, 2012.

Sarkhot, D. V., Ghezzehei, T. A., and Berhe, A. A.: Effectiveness of Biochar for Sorption of Ammonium and Phosphate from Dairy Effluent, J. Environ. Qual., 42, 1545-1554, 2013. 
Spokas, K. A., Novak, J. M., and Venterea, R. T.: Biochar's role as an alternative $\mathrm{N}$-fertilizer: ammonia capture $\mathrm{NH}_{3}$, Plant Soil, 350, 35-42, 2011.

Steinbeiss, S., Gleixner, G., and Antonietti, M.: Effect of biochar amendment on soil carbon balance and soil microbial activity, Soil Biol. Biochem., 41, 1301-1310, 2009.

Taghizadeh-Toosi, A., Clough, T. J., Sherlock, R. R., and Condron, L. M.: Biochar adsorbed ammonia is bioavailable, Plant Soil, 350, 57-69, 2011.

Titirici, M. M., Antonietti, M., and Baccile, N.: Hydrothermal carbon from biomass: a comparison of the local structure from poly- to monosaccharides and pentoses/hexoses, Green Chem., 10, 1204-1212, 2008.
Wang, L. L., Guo, Y. P., Zhu, Y. C., Li, Y., Qu, Y. N., Rong, C. G., Ma, X. Y., and Wang, Z. C.: A new route for preparation of hydrochars from rice husk, Bioresource Technol., 101, 98079810, 2010.

Wiedner, K., Naisse, C., Rumpel, C., Pozzi, A., Wieczorek, P., and Glaser, B.: Chemical modification of biomass residues during hydrothermal carbonization - What makes the difference, temperature or feedstock?, Org. Geochem., 54, 91-100, 2013.

Xu, G., Sun, J., Shao, H., and Chang, S. X.: Biochar had effects on phosphorus sorption and desorption in three soils with differing acidity, Ecol. Eng., 62, 54-60, 2014.

Yao, Y., Gao, B., Zhang, M., Inyang, M., and Zimmerman, A. R.: Effect of biochar amendment on sorption and leaching of nitrate, ammonium, and phosphate in a sandy soil $\mathrm{NO}_{3}, \mathrm{NH}_{4}, \mathrm{PO}_{4}$, Chemosphere, 89, 1467-1471, 2012. 